\section{Clot Characterization by Noncontrast CT to Predict IV tPA} Failure

We have read the recent article entitled "Quantification of Thrombus Hounsfield Units on Noncontrast CT Predicts Stroke Subtype and Early Recanalization after Intravenous Recombinant Tissue Plasminogen Activator" by Puig et al with great interest. ${ }^{1}$ We congratulate the authors on their analysis, in which they found that relative Hounsfield unit attenuation of MCA clot was the best predictor of IV tPA failure, with an optimal threshold $<1.38$. Furthermore, they found that thrombus length was not associated with IV tPA response (see Online Table 1 in Puig et $\mathrm{al}^{1}$ ). This last finding is at odds with a recent study supporting a strong effect of clot length on the likelihood of IV tPA recanalization. ${ }^{2}$ In that study of 138 patients, clots longer than 8 $\mathrm{mm}$ (as determined by thin-section NCCT) had a $<1 \%$ chance of opening.

We offer a likely explanation for this disagreement. Puig et $\mathrm{al}^{1}$ measured clot length on axial thick-slab maximum-intensity-projection data from the CTA datasets. We believe that this method is prone to considerable measurement error because it relies on contrast to opacify the distal end of the clot. The degree to which contrast approaches the distal clot face, in turn, is dependent on the strength of the pial collateral circulation, which is often compromised and, in many cases, does not reach the occluded vessel segment. Indeed, in an angiographic study by Christoforidis et al, ${ }^{3}$ only 27 of 53 (51\%) patients demonstrated sufficient collaterals to opacify the distal clot face. Therefore, it is highly likely that Puig et al overestimated clot length in many instances. To address this problem, we suggest that the authors determine clot length by using their NCCT data with a section thickness no greater than $2.5 \mathrm{~mm}$ (which they can achieve given their
0.75 -mm collimation). On the basis of recent data, ${ }^{4}$ partial volume effects introduce significant error in clot-length determination at greater section widths. For similar reasons, it may be better to measure Hounsfield attenuation by using section thicknesses smaller than the 3-mm sections used in their study. It would be interesting to see whether this re-analysis will confirm the importance of clot length on IV tPA responsiveness and whether clot attenuation provides additional prognostic information.

\section{References}

1. Puig J, Pedraza S, Demchuk A, et al. Quantification of thrombus Hounsfield units on noncontrast CT predicts stroke subtype and early recanalization after intravenous recombinant tissue plasminogen activator. AJNR Am J Neuroradiol 2011;33:90-96. Epub 2011 Dec 8

2. Riedel CH, Zimmermann P, Jensen-Kondering $U$, et al. The importance of size: successful recanalization by intravenous thrombolysis in acute anterior stroke depends on thrombus length. Stroke 2011;42:1775-77

3. Christoforidis GA, Mohammad Y, Kehagias D, et al. Angiographic assessment of pial collaterals as a prognostic indicator following intra-arterial thrombolysis for acute ischemic stroke. AJNR Am J Neuroradiol 2005;26:1789-97

4. Riedel CH, Jensen U, Rohr A, et al. Assessment of thrombus in acute middle cerebral artery occlusion using thin-slice nonenhanced computed tomography reconstructions. Stroke 2010;41:1659-64

C.H. Riedel

Department of Neuroradiology

University of Kiel

Kiel, Germany

A.J. Yoo

Division of Interventional and Diagnostic Neuroradiology Massachusetts General Hospital Harvard Medical School

Boston, Massachusetts

http://dx.doi.org/10.3174/ajnr.A3041 